\title{
Hemodynamic effects of left pulmonary artery stenosis after superior cavopulmonary connection: A patient-specific multiscale modeling study
}

\author{
Daniele E. Schiavazzi, $\mathrm{PhD},{ }^{\mathrm{a}}$ Ethan O. Kung, $\mathrm{PhD},{ }^{\mathrm{a}}$ Alison L. Marsden, $\mathrm{PhD},{ }^{\mathrm{a}}$ \\ Catriona Baker, BSc, MBBS, MRCS, ${ }^{\mathrm{b}}$ Giancarlo Pennati, PhD, ${ }^{\mathrm{c}}$ Tain-Yen Hsia, MD, MSc, ${ }^{\mathrm{b}}$ \\ Anthony Hlavacek, MD, ${ }^{\mathrm{d}}$ and Adam L. Dorfman, MD, ${ }^{\mathrm{e}}$ for the Modeling of Congenital Hearts Alliance \\ (MOCHA) Investigators
}

Objective: Currently, no quantitative guidelines have been established for treatment of left pulmonary artery (LPA) stenosis. This study aims to quantify the effects of LPA stenosis on postoperative hemodynamics for single-ventricle patients undergoing stage II superior cavopulmonary connection (SCPC) surgery, using a multiscale computational approach.

\begin{abstract}
Methods: Image data from 6 patients were segmented to produce 3-dimensional models of the pulmonary arteries before stage II surgery. Pressure and flow measurements were used to tune a 0-dimensional model of the entire circulation. Postoperative geometries were generated through stage II virtual surgery; varying degrees of LPA stenosis were applied using mesh morphing and hemodynamics assessed through coupled 0-3-dimensional simulations. To relate metrics of stenosis to clinical classifications, pediatric cardiologists and surgeons ranked the degrees of stenosis in the models. The effects of LPA stenosis were assessed based on left-to-right pulmonary artery flow split ratios, mean pressure drop across the stenosis, cardiac pressure-volume loops, and other clinically relevant parameters.
\end{abstract}

Results: Stenosis of $>65 \%$ of the vessel diameter was required to produce a right pulmonary artery:LPA flow split $<30 \%$, and/or a mean pressure drop of $>3.0 \mathrm{~mm} \mathrm{Hg}$, defined as clinically significant changes.

Conclusions: The effects of $<65 \%$ stenosis on SCPC hemodynamics and physiology were minor and may not justify the increased complexity of adding LPA arterioplasty to the SCPC operation. However, in the longer term, pulmonary augmentation may affect outcomes of the Fontan completion surgery, as pulmonary artery distortion is a risk factor that may influence stage III physiology. (J Thorac Cardiovasc Surg 2015;149:689-96)

See related commentary on pages $697-8$

Supplemental material is available online.

During stage II superior cavopulmonary connection (SCPC), significant left pulmonary artery (LPA) hypoplasia or stenosis is often relieved by surgical arterioplasty or postoperative

\footnotetext{
From the Mechanical and Aerospace Engineering Department, ${ }^{a}$ University of California, San Diego, San Diego, Calif; Great Ormond Street Hospital for Children $^{\mathrm{b}}$ and Great Ormond Street Hospital for Children, NHS Foundation Trust, London, United Kingdom; Department of Chemistry, ${ }^{\mathrm{c}}$ Materials and Chemical Engineering, Politecnico di Milano, Milano, Italy; Department of Pediatrics, ${ }^{\mathrm{d}}$ Medical University of South Carolina, Charleston, SC; and Department of Pediatrics, ${ }^{\mathrm{e}}$ University of Michigan Medical School, Ann Arbor, Mich.

This work was supported by the Leducq Foundation as part of the Transatlantic Network of Excellence for Cardiovascular Research; a Burroughs Wellcome Fund Career Award at the Scientific Interface; and National Science Foundation CAREER OCI-1150184.

Disclosures: Authors have nothing to disclose with regard to commercial support.

MOCHA Investigators: Andrew Taylor, MD; Alessandro Giardini, MD; Sachin Khambadkone, MD; Silvia Schievano, PhD; Marc de Leval, MD; and T.-Y. Hsia, MD (Great Ormond Street Hospital for Children, NHS Foundation Trust, London,
}

stenting. ${ }^{1-5}$ However, the addition of LPA arterioplasty to the SCPC operation can add substantial time and complexity, and the minimal degree of LPA stenosis that warrants accepting this increased risk, to ensure optimal postoperative SCPC hemodynamics, is unclear. Thus, current clinical decisions surrounding treatment of LPA stenosis are often subjective, relying on visual inspection of angiography data and clinical experience.

Prior studies have suggested that energy-loss minimization should be a primary metric for treatment planning,

United Kingdom); Edward Bove, MD, and Adam Dorfman, MD (University of Michigan, Ann Arbor, Mich); G. Hamilton Baker, MD, and Anthony Hlavacek (Medical University of South Carolina, Charleston, SC); Francesco Migliavacca, $\mathrm{PhD}$, Giancarlo Pennati, PhD, and Gabriele Dubini, PhD (Politecnico di Milano Milan, Italy); Alison Marsden, PhD (University of California, San Diego, San Diego, Calif); Irene Vignon-Clementel (INRIA, Paris, France); Richard Figliola, $\mathrm{PhD}$, and John McGregor, $\mathrm{PhD}$ (Clemson University, Clemson, SC).

Received for publication July 14, 2014; revisions received Aug 20, 2014; accepted for publication Aug 22, 2014; available ahead of print Feb 4, 2015.

Address for reprints: Adam L. Dorfman, MD, University of Michigan Congenital Heart Center, C.S. Mott Children's Hospital, 1540 E Hospital Dr, Ann Arbor, MI 48109-4204 (E-mail: adamdorf@med.umich.edu). $0022-5223 / \$ 36.00$

Copyright $(C) 2015$ by The American Association for Thoracic Surgery http://dx.doi.org/10.1016/j.jtcvs.2014.12.040 


$$
\begin{aligned}
& \text { Abbreviations and Acronyms } \\
& \begin{aligned}
\text { LPA } & =\text { left pulmonary artery } \\
\text { LPN } & =\text { lumped parameter network } \\
\text { PV-loop } & =\text { pressure-volume loop } \\
\text { RPA } & =\text { right pulmonary artery } \\
\text { SCPC } & =\text { superior cavopulmonary connection } \\
\text { 3-D } & =3 \text {-dimensional }
\end{aligned}
\end{aligned}
$$

and they have demonstrated large differences in energy loss with the addition of stenosis, and in hemi-Fontan compared with SCPC surgery. ${ }^{6}$ However, these studies often failed to consider global physiology, examining primarily local hemodynamics. To address these issues, we performed patient-specific multiscale numeric simulations to quantify the effects of systematically varying LPA stenosis on SCPC hemodynamics and physiology. This study aims to be a first step toward developing quantitative guidelines for treatment of LPA stenosis.

\section{METHODS}

\section{Acquisition of Preoperative Stage II Clinical Data}

Patients were enrolled prospectively as part of a multicenter collaboration, and study patients were drawn from 3 participating clinical centers. The study was approved by the institutional review board of each participating clinical center, and informed consent was obtained for each participating patient. Table 1 summarizes the age, body surface area, diagnosis, performed surgery, MRI, and catheter measurements for the 6 patients included in the study.

\section{Three-Dimensional Cavopulmonary Junction Models}

Three-dimensional (3-D) models of the junction between BlalockTaussig shunt and pulmonary arteries were created using commercial software (Mimics, Materialise NV, Leuven, Belgium) from the MRI data of each patient before the stage II surgery. A combined segmentation and region-growing technique was adopted, resulting in the 3-D volumes of the relevant vasculature. ${ }^{7}$ These preoperative geometries were manipulated to obtain virtual postoperative surgical anatomies, accounting for the geometric constraints imposed by organs and vessels surrounding the modeled region. Using this method, 2 postoperative 3-D geometric models were generated for each patient, representing the hemi-Fontan and Glenn surgical options (Figure 1, A).

All virtual surgeries were performed under the guidance of a pediatric cardiac surgeon and were approved by a second surgeon from our research group. Although patient-specific models of the stage II anatomy could be constructed directly from catheterization and MRI data, the need to perform these 2 tests in a postoperative patient within a short time period is difficult to justify. Therefore, these clinical situations do not allow parameter tuning of complete multiscale models.

\section{Multiscale Model}

A circuit analogy was used to construct a lumped parameter network (LPN) model $^{8}$ to simulate patients' circulatory physiology in stage I (preoperative) and stage II (postoperative), following our previous work,,$^{9-12}$ providing transient boundary data for the fluid dynamic analysis of the 3-D superior vena cava-pulmonary artery junction model. The LPN consists of a system of algebraic and ordinary differential equations (Figure 1, B). Five main circuit blocks are included, characterizing the heart, and the systemic (ie, upper and lower body) and pulmonary (ie, left and right) circulations. ${ }^{13}$ Active and passive curves, along with activation functions, model the atrial and ventricular contraction, whereas nonlinear diodes mimic atrioventricular and aortic valves. Coronary circulation, gravity, and respiratory effects were neglected. ${ }^{14}$ Semiautomated tuning was performed to identify the set of LPN parameters that matched clinical data for each patient (Table E1). The LPN model was implicitly coupled to a custom 3-D Streamline Upwind Petrov-Galerkin finite-element Navier-Stokes solver from the SimVascular project. ${ }^{15,16}$ Blood was assumed to be Newtonian with a density of $1060 \mathrm{~kg} / \mathrm{m}^{3}$ and a dynamic viscosity of $0.004 \mathrm{~Pa} \cdot \mathrm{s}$.

Rigid-wall simulations were performed with Neumann boundary conditions at all inlets and outlets. Stabilization was applied at coupled velocity-pressure surfaces to prevent numeric divergence due to backflow. ${ }^{17}$ The discrete algebraic system of equations was solved iteratively, using a bipartitioned algorithm with a dedicated preconditioner. $^{18}$

\section{Simulations With Varying Degrees of Stenosis}

Various configurations of stenosis, in either the main pulmonary arteries or their branches, were observed in 90 patients in a prior study ${ }^{19}$ that combined direct clinical observation and literature data. These data showed that the occurrence of a discrete pulmonary artery stenosis was particularly frequent when combined with other cardiac anomalies. In this patient population, distortion in the LPA often results from local compression induced by the augmentation of the aorta performed during stage I surgery, ${ }^{2,3,20}$ which affects ventricular-arterial coupling ${ }^{21}$ and often results in "Gothic" arch configurations characterized by increased and eccentric wall shear stresses. ${ }^{22}$ Under idealized flow conditions in a cylindrical vessel, pressure drop and resistance vary linearly with the length of the stenosis, but they vary with the fourth power of the radius.

We therefore chose to focus on discrete stenosis, which we consider to be the geometric quantity that can be expected to produce the most significant variation in hemodynamics. The degree of a discrete stenosis is defined, based on vessel area and diameter, respectively, as follows:

$$
\mathrm{sA}=100\left(1-\mathrm{A}_{\min } / \mathrm{A}_{\mathrm{ref}}\right), \quad \mathrm{sd}=100\left(1-\mathrm{d}_{\min } / \mathrm{d}_{\mathrm{ref}}\right),
$$

where $\mathrm{A}_{\min }$ and $\mathrm{d}_{\min }$ are the area and diameter, respectively, at the location of minimal vessel lumen area, and $\mathrm{A}_{\text {ref }}$ and $\mathrm{d}_{\text {ref }}$ are reference values for area and diameter, respectively. Figure $1, C$ shows 2 possible choices for $A_{\text {ref. }}$ In our study, results are reported using a diameter-based metric, and $\mathrm{d}_{\mathrm{ref}, 2}$ as a reference value. Models were manipulated systematically through an automated morphing technique to achieve the desired stenosis levels. Finally, simulations were performed for each, with 6 degrees of stenosis, for a total of 48 simulations (including both hemi-Fontan and Glenn surgical outcomes for patients $\mathrm{P} 1$ and $\mathrm{P} 3$ ), using the multiscale modeling methods described earlier.

\section{Survey Analysis}

Visual inspection constitutes the most immediate method of assessment for the severity of LPA stenosis in clinical practice and drives the collection of supplemental (often invasively obtained) information on blood flow or pressure. Therefore, a web-based survey was designed to correlate the quantitative definition of stenosis used in our study with clinical judgment. Nine clinicians, including specialists in pediatric cardiology and pediatric cardiovascular surgery, were asked to rank the degree of stenosis of the LPA in 10 pictures of rendered, 3-D morphed anatomic models (Figure 1, A) of bidirectional Glenn surgical anatomies, all shown in the same view. These models, a subset of the 36 total Glenn models, represented 4 possible classes of stenosis (ie, minimal, mild, moderate, and severe); they included 3 models with stenosis in the range 
TABLE 1. Clinical data for the 6 patients considered in the present study

\begin{tabular}{|c|c|c|c|c|c|c|}
\hline Patient & P1 & $\mathbf{P 2}$ & $\mathbf{P 3}$ & $\mathbf{P 4}$ & P5 & P6 \\
\hline $\begin{array}{l}\text { Age at stage II } \\
\text { surgery (mo) }\end{array}$ & 6 & 5 & 4 & 3 & 4 & 5 \\
\hline $\operatorname{BSA}\left(\mathrm{m}^{2}\right)$ & 0.34 & 0.3 & 0.27 & 0.26 & 0.28 & 0.34 \\
\hline Diagnosis & $\begin{array}{l}\text { Pulmonary atresia } \\
\text { with intact } \\
\text { ventricular septum }\end{array}$ & $\begin{array}{l}\text { HLHS (mitral and } \\
\text { aortic stenosis), } \\
\text { central PA stenosis }\end{array}$ & $\begin{array}{r}\text { HLHS (aortic stenosis } \\
\text { and mitral stenosis) }\end{array}$ & $\begin{array}{l}\text { Tricuspid and } \\
\text { pulmonary atresia, } \\
\text { LPA stenosis }\end{array}$ & $\begin{array}{l}\text { HLHS (aortic } \\
\text { atresia) }\end{array}$ & $\begin{array}{l}\text { HLHS (aortic atresia } \\
\text { mitral hypoplasia) }\end{array}$ \\
\hline Stage I surgery & $\begin{array}{l}\text { Central shunt (aorta } \\
\text { to PA) }\end{array}$ & $\begin{array}{l}\text { Norwood procedure } \\
\text { with } 3.5-\mathrm{mm} \\
\text { rmBTS }\end{array}$ & $\begin{array}{l}\text { Norwood procedure } \\
\text { with } 3.5-\mathrm{mm} \\
\text { rmBTS }\end{array}$ & $\begin{array}{l}\text { LPA patch plasty } \\
\text { 4-mm rmBTS }\end{array}$ & $\begin{array}{l}\text { Norwood } \\
\text { procedure } \\
\text { with } 3.5-\mathrm{mm} \\
\text { rmBTS }\end{array}$ & $\begin{array}{l}\text { Norwood procedure } \\
\text { with } 3.5-\mathrm{mm} \\
\text { rmBTS }\end{array}$ \\
\hline MRI & $\begin{array}{l}\text { Immediately before } \\
\text { surgery USGA }\end{array}$ & 1.5 mo before surgery & $\begin{array}{l}1 \text { mo before surgery } \\
\text { USGA as catheter }\end{array}$ & $\begin{array}{l}1 \text { mo before surgery } \\
\text { USGA as catheter }\end{array}$ & $\begin{array}{l}\text { Immediately } \\
\text { before surgery } \\
\text { USGA }\end{array}$ & $\begin{array}{l}\text { Immediately before } \\
\text { surgery USGA }\end{array}$ \\
\hline $\begin{array}{l}\text { Cardiac } \\
\text { catheterization }\end{array}$ & $3 \mathrm{~d}$ before surgery & $\begin{array}{l}1.5 \text { mo before surgery } \\
\text { (USGA as MRI) }\end{array}$ & $\begin{array}{c}1 \text { mo before surgery } \\
\text { (USGA as MRI) }\end{array}$ & $\begin{array}{c}1 \text { mo before surgery } \\
\text { (USGA as MRI) }\end{array}$ & $\begin{array}{l}1.5 \text { mo before } \\
\text { surgery }\end{array}$ & $1 \mathrm{wk}$ before surgery \\
\hline Stage II surgery & $\begin{array}{l}\text { Hemi-Fontan } \\
\text { procedure with } \\
\text { patch augmentation } \\
\text { of LPA }\end{array}$ & $\begin{array}{l}\text { Bidirectional Glenn, } \\
\text { central PA } \\
\text { augmented with } \\
\text { pulmonary } \\
\text { homograft }\end{array}$ & Bidirectional Glenn & $\begin{array}{l}\text { Bidirectional Glenn } \\
\text { with patch } \\
\text { augmentation of } \\
\text { the LPA }\end{array}$ & Hemi-Fontan & $\begin{array}{l}\text { Hemi-Fontan } \\
\text { procedure with } \\
\text { patch augmentation } \\
\text { of branch PA }\end{array}$ \\
\hline
\end{tabular}

$P$, Patient (Pl, patient 1, etc); USGA, under the same general anaesthetic; BSA, body surface area; $H L H S$, hypoplastic left heart syndrome; $L P A$, left pulmonary artery $P A$, pulmonary artery; $r m B T S$, right modified Blalock-Taussig shunt; $M R I$, magnetic resonance imaging.

$30 \%-45 \%$ (diameter-based); 4 with $55 \%-60 \%$; and 3 with $70 \%-80 \%$, allowing average degrees of stenosis and associated ranges to be computed for each class (Table E2). Assuming degrees of stenosis to be uniformly distributed within these ranges, the corresponding variability in the 2 hemodynamic indicators of interest was determined through Monte Carlo simulation. For every randomly selected degree of stenosis, the associated LPA:RPA flow split ratio and pressure drop were determined by interpolating interpatient average results from the previously computed multiscale numeric simulations.

\section{RESULTS}

Figure 2 shows the left pulmonary flow split ratio (Figure 2, $A$ ) and pressure drops (Figure 2, $B$ ) for all models. The LPA:RPA flow split ratio in patient P1 was weakly affected by the severity of the stenosis (Figure 2, A). Comparing the ratio between flow splits at $80 \%$ stenosis and $35 \%$ stenosis, the value for patient P1 was higher (0.75) than the average value for the other patients $(0.36)$. A maximum relative difference of $4 \%$ in flow split ratio was observed between Glenn and hemi-Fontan models across all levels of stenosis in patients P1 and P3. Comparison between hemi-Fontan and Glenn surgical options was limited to these 2 patients to support the validity of the results across the 2 most common surgical options. The comparison was not performed on all patients, as this was not the main focus of the study. The maximum relative difference in pressure drop across the LPA was higher, at $10 \%$ for degrees of stenosis $>60 \%$ in diameter, ie, when the effects of the discrete stenosis become more important than those produced by the underlying surgical configuration. For lower degrees of stenosis, higher differences are associated with limited pressure drops.
Interpatient averages and SDs of flow split ratios and mean pressure drop in the LPA are illustrated in Figure 3. Percentage flow to the LPA $<30 \%$ and/or a mean pressure drop $>3.0 \mathrm{~mm} \mathrm{Hg}$ across the stenosis are defined to be clinically significant. ${ }^{4}$ These critical values of flow reduction and pressure drop are observed only for high degrees of stenosis at more than $69.2 \% \pm 7.0 \%$ (LPA:RPA flow split ratio), $61.9 \% \pm 7.3 \%$ (mean pressure drop), and $65.5 \% \pm 7.9 \%$ (both indicators assumed to be of equal importance), based on diameter. In addition, an increase in the SD of the pressure drop is observed with increasing severity of the stenosis (Figure 3, $B$ ), whereas the flow split ratio SD remains relatively constant (Figure $3, A$ ).

The effects of varying degrees of stenosis on the pressure-volume (PV)-loop are illustrated in Figure 4. The PV-loop curves were nearly unchanged, even for severe levels of stenosis. No significant changes were observed in other clinically relevant quantities, such as pulmonary-tosystemic flow ratio, and systemic and venous oxygen saturation (Table E3). Power losses varied significantly, despite minimal changes in the other indicators. Figure E1 correlates the computed hemodynamic quantities with a classification of the degrees of stenosis based on survey data. A clinical classification of a "severe" stenosis, based on visual inspection, is associated with large variations in the LPA:RPA flow split ratio and pressure drop across the stenosis.

\section{DISCUSSION}

Using multiscale computational modeling and geometric morphing, we have systematically quantified the hemodynamic consequences of LPA stenosis in a cohort of 6 

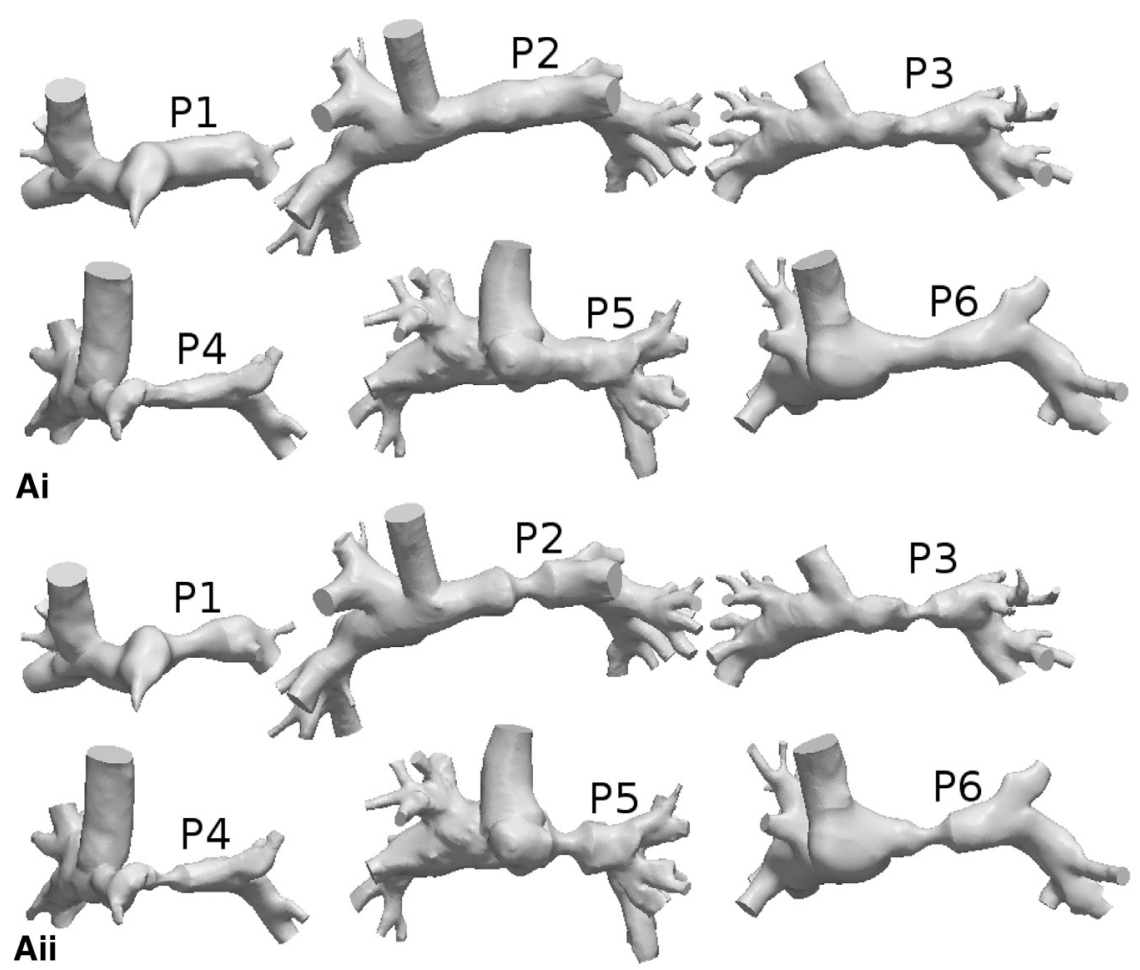

FIGURE 1. A, Models for all 6 patients, without stenosis (A, i), and with approximately $65 \%$ stenosis (A, ii). B, Schematic of the multiscale model used for simulating local hemodynamics and global circulation in the 6 patients. C, Possible definitions of degree of stenosis in the computational model. $P$, Patient; $Q_{U B}$, venous upper body flow rate; $R_{U B}$, venous upper body resistance; $P_{U B}$, upper body pressure; $L_{U B A}$, arterial upper body inductance; $R_{U B A}$, arterial upper body resistance; $C_{U B}$, upper body capacitance; $P_{S V C}$, pressure in superior vena cava; $C_{S V C}$, superior vena cava compliance; $Q_{S V C}$, superior vena cava flow rate; $R C R$, resistance-compliance-resistance; $Q_{P}$, proximal flow rate in pulmonary block; $R_{P}$, proximal resistance in pulmonary block; $P_{C}$, pulmonary block pressure; $R_{d}$, distal resistance in pulmonary block; $Q_{d}$, distal flow rate in pulmonary block; $Q_{C}$, capacitor flow rate in pulmonary block; $C$, pulmonary block capacitance; $Q_{L P V}$, left pulmonary venous flow rate; $Q_{R P V}$, right pulmonary vanous flow rate; $Q_{P V}$, total pulmonary venous flow rate; $Q_{U B A}$, arterial upper body flow rate; $P_{S A}$, atrial pressure; $L_{A V}$, atrio-ventricular inductance; $K_{A V}$, atrio-ventricular resistance; $P_{S V}$, ventricular pressure; $R_{M Y O}$, myocardial resistance; $K_{A O}$, aortic resistance; $Q_{A O}$, aortic flow rate; $P_{A O}$, aortic pressure; $Q_{A V}$, atrio-ventricular flow rate; $Q_{S V i n}$, ventricular inflow; $C_{A O}$, aortic compliance; $Q_{T H I V C}$, flow rate in thoracic inferior vena cava; $E_{S A}$, atrial model parameters; $E_{S V}$, ventricular model parameters; $Q_{T H A O}$, thoracic aorta flow rate; IVC, inferior vena cava; $R_{T H A O}$, thoracic aorta resistance; $R_{T H I V C}$, thoracic inferior vena cava resistance; $Q_{L V}$, hepatic venous flow rate; $R_{L V}$, hepatic venous resistance; $P_{L}$, hepatic pressure; $R_{L A}$, hepatic arterial resistance; $Q_{L A}$, hepatic arterial flow rate; $L_{T H A O}$, thoracic aorta inductance; $C_{L}$, hepatic compliance; $P_{T H I V C}$, thoracic inferior vena cava pressure; $P_{T H A O}$, pressure in thoracic aorta; $C_{T H A O}$, compliance in thoracic aorta; $C_{T H V C}$, compliance in thoracic inferior vena cava; $R_{K V}$, renal venous resistance; $P_{K}$, renal pressure; $R_{K A}$, renal arterial resistance; $Q_{K A}$, renal arterial flow rate; $R_{A B A O}$, resistance in abdominal aorta; $R_{A B I V C}$, resistance in abdominal inferior vena cava; $Q_{K V}$, renal venous flow rate; $C_{K}$, renal compliance; $Q_{A B A O}$, flow rate in abdominal aorta; $Q_{A B I V C}$, flow rate in abdominal inferior vena cava; $L_{A B A O}$, inductance in abdominal aorta; $P_{A B I V C}$, pressure in abdominal inferior vena cava; $R_{I V}$, venous resistance in the intestine; $P_{I}$, pressure in the intestine; $R_{I A}$, arterial resistance in the intestine; $C_{A B A O}$, compliance of abdominal aorta; $C_{A B I V C}$, compliance of abdominal inferior vena cava; $Q_{I V}$, venous flow rate in the intestine; $C_{I}$, intestine compliance; $Q_{I A}$, arterial flow in the intestine; $P_{A B A O}$, pressure in the abdominal aorta; $R_{L E G V}$, lower body venous resistance; $P_{L E G V}$, lower body venous pressure; $Q_{L E G C}$, lower body capillary flow rate; $R_{L E G C}$, lower body capillary resistance; $P_{L E G A}$, lower body arterial pressure; $L_{L E G A}$, lower body arterial inductance; $R_{L E G A}$, lower body arterial resistance; $Q_{L E G A}$, lower body arterial flow rate.

stage II single-ventricle patients. In contrast to many prior studies focused on only local hemodynamics, multiscale methods can be used to assess changes in the global circulation as well as local hemodynamics. Multiple quantities were extracted from simulation results, including local power loss, changes in flow split, pressure drops, and cardiac PV loops. The most important finding is that a degree of stenosis $>65 \%$, based on diameter, leads to mean LPA:RPA flow split and pressure drop values in the range of clinical concern, as defined by a flow split of
$<30 \%$ and/or a pressure drop of $>3.0 \mathrm{~mm} \mathrm{Hg}$. However, even for stenosis levels reaching $80 \%$ (diameter-based), essentially no change occurred in PV loops or other global quantities of clinical interest.

This study is motivated by the frequent clinical need for augmentation of the pulmonary arteries during stage II surgery and subsequent procedures. Pulmonary artery distortion and hypoplasia, occurring most often in the LPA, is a common complication incurred along the Fontan clinical pathway, requiring late pulmonary artery 


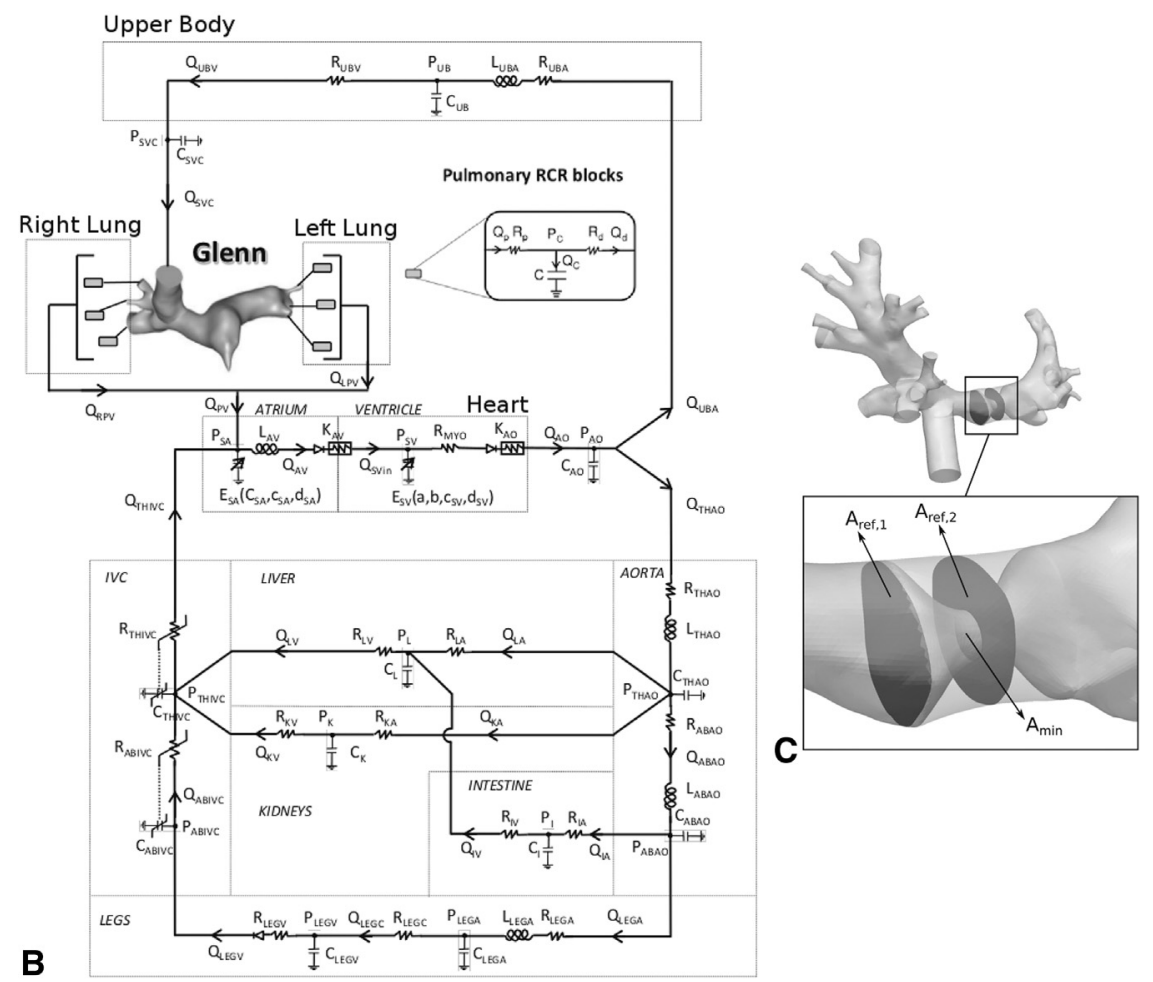

FIGURE 1. (continued).

reconstruction in $>50 \%$ of cases, ${ }^{3,4}$ and balloon dilatation or stenting in nearly one third of cases. ${ }^{4}$ Although some studies have shown no statistical difference in mortality in stage II patients undergoing pulmonary artery plasty, ${ }^{1}$ perioperative augmentation of the pulmonary arteries is well known to add significant complexity to the surgery, with reported bypass time increasing to $151 \pm 65 \mathrm{~min}$ with LPA plasty, versus $95 \pm 50$ min without it. ${ }^{3}$

Augmentation of the central pulmonary arteries is considered an important component in stage II surgery, and minimization of pulmonary artery distortion is a primary factor in the choice to use the hemi-Fontan rather than the bidirectional Glenn procedure in some centers. ${ }^{2}$ Despite the increased surgical complexity and inherent risks of additional procedures, aggressive treatment of pulmonary stenosis is often pursued to avoid potential adverse effects on exercise tolerance and suboptimal growth and remodeling caused by reduced flow. ${ }^{23,24}$ However, pulmonary arterioplasties continue to be performed based on subjective criteria at the time of surgery and preoperative angiographic appearance. Therefore, quantitative assessment of the hemodynamic

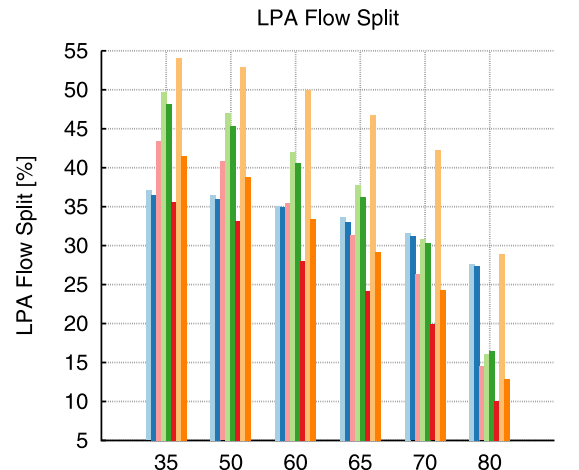

A Stenosis Level - Definition using vessel diameter [\%]
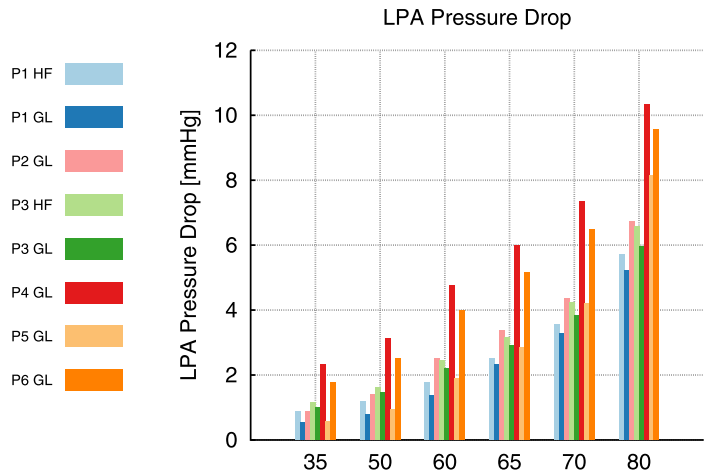

B Stenosis Level - Definition using vessel diameter [\%]

FIGURE 2. A, LPA flow split ratio; and (B) mean pressure drop resulting from all numerical simulations. A diameter-based definition of the degree of stenosis is employed using $\mathrm{d}_{\mathrm{ref}, 2}$. $L P A$, Left pulmonary artery; $P$, patient; $G L$, bidirectional Glenn surgery; $H F$, hemi-Fontan surgery. 

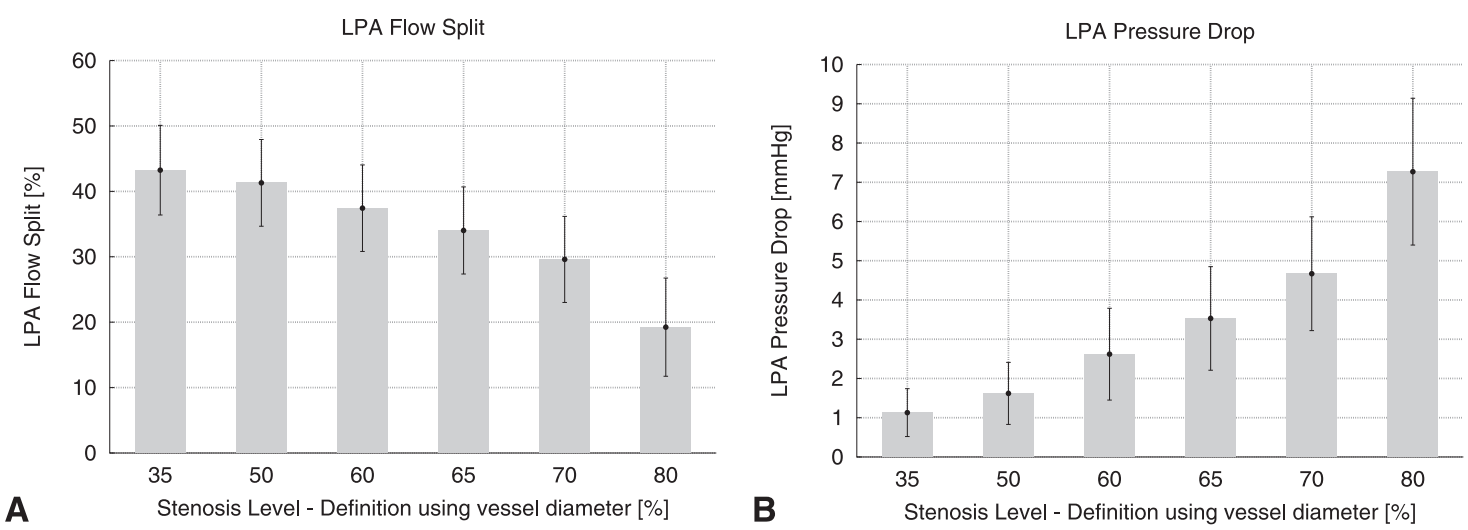

FIGURE 3. Mean value and SD of (A) LPA flow split ratio; and (B) pressure drop results across all patients. A diameter-based definition of the degree of stenosis is employed using $\mathrm{d}_{\mathrm{ref}, 2}$. The pressure drop SD increases with increasing stenosis severity. An opposite trend is observed for the LPA flow split ratio. Error bars are based on $1 \mathrm{SD}$. LPA, Left pulmonary artery.

and physiologic impact of LPA stenosis is needed to better select patients for treatment.

Our simulations enabled testing that is not possible in vivo, as the degree of stenosis could be varied systematically, keeping all other modeling parameters fixed. Our results show that power loss in the superior vena cava-pulmonary artery junction constitutes only a small fraction of the overall pulmonary power loss and ventricular work. Therefore, although relative differences in power loss with even mild stenosis may be large, alterations in the total pulmonary vascular resistance are produced with only significant LPA stenosis. Although prior studies have reported significant changes in power loss, suggesting that power loss should be a primary determinant of surgical decision making, these results often did not include a complete boundary circulation model, and therefore the consequences on global physiology could not be assessed. ${ }^{6}$

Our results show that the ventricular function and PV loops remain essentially unaltered, even with severe stenosis (Figure 4). This finding is explained by the fact that the losses in the anatomic model represent only a small percentage of the total ventricular power for a wide range of severity of pulmonary artery stenosis. In accordance with this finding, other parameters of potential clinical interest, including the pulmonary-to-systemic flow ratio and oxygen saturations, remained nearly unchanged as well. As noted, this result is not surprising from an engineering point of view, because the local power losses induced by even significant degrees of stenosis represent only a tiny fraction of the total ventricular power.

An examination of patient-specific results showed that the LPA:RPA flow split in patient P1 was less sensitive to LPA stenosis compared with that in other patients. For this patient, the ratio between left (Rl) and right pulmonary resistances $(\mathrm{Rr})$ is the highest among all models $(\mathrm{R} 1 / \mathrm{Rr}=1.72)$. Accordingly, the power loss in the 3-D model for an $80 \%$ (diameter-based) degree of stenosis is $2.069 \mathrm{~mW}$ for patient $\mathrm{P} 1$, which is only about $11.5 \%$ of the total pulmonary power loss, the smallest percentage
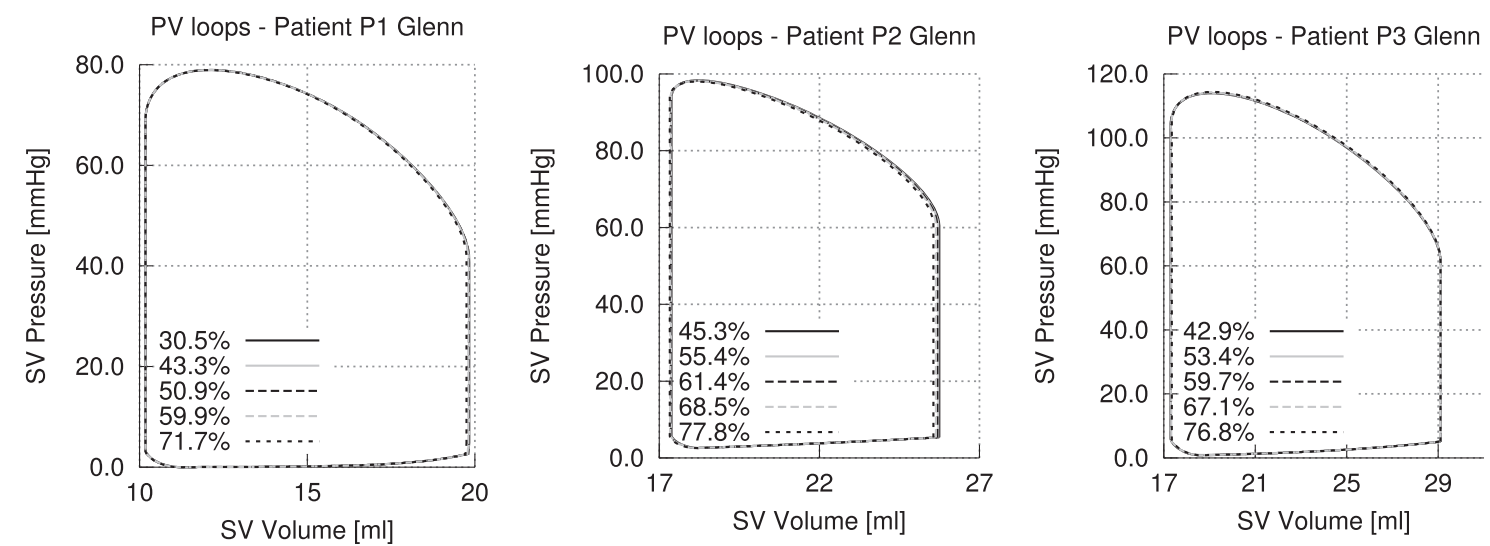

FIGURE 4. PV-loops with varying degrees of stenosis, demonstrating nearly zero change in cardiac work with increasing severity. A diameter-based definition of the degree of stenosis is employed using $\mathrm{d}_{\mathrm{ref}, 2}$. Results are limited to 1 patient per recruitment institution and refer to virtual bidirectional Glenn surgery. $P V$, Pressure-volume; $S V$, single ventricle. 
found in any of the models (P2: $11.8 \%$; P3: $24.8 \%$; P4: $13.5 \%$; P5: $25.0 \%$; P6: $14.2 \%$ ). The mean value of this quantity was $16.7 \% \pm 5.3 \%$ for the 6 patients, confirming that local power losses are on average only a small fraction of total pulmonary power losses. The ratio $\mathrm{Rl} / \mathrm{Rr}$ (ranging from 1.72 to 0.79$)$ also explains why $\mathrm{P} 5(\mathrm{Rl} / \mathrm{Rr}=1.38)$ and $\mathrm{P} 4(\mathrm{R} 1 / \mathrm{Rr}=0.79)$ show the highest and lowest flow split ratios, respectively.

The local superior vena cava-pulmonary artery junction configuration directly affects the pressure drop across the LPA. This change can be seen, for example, in patient P4, for whom distortion in the pulmonary arteries induces a pressure drop of about $2.0 \mathrm{~mm} \mathrm{Hg}$, even with minimal stenosis (Figure 1, A). The SD of the mean pressure drop was substantially larger than that of the flow split ratio, with increasing stenosis severity, indicating higher interpatient variability of pressure drop (Figure 3, $A$ and $B$ ) related to a higher sensitivity of the mean pressure drop to local geometric variations in the anatomic model. LPA:RPA flow splits are instead affected predominantly by values of the downstream resistance and by the relative relationship between local (ie, in the superior vena cava-pulmonary artery junction) and global power losses.

Assembling statistics for all patients in the cohort, we find that a stenosis degree of $>65 \%$ is required to induce flow splits of $<30 \%$ and pressure drops of $>3.0 \mathrm{~mm} \mathrm{Hg}$, which we consider in this study to be clinically significant. This finding is consistent with the observation that only severe stenoses produce meaningful alterations in the pulmonary vascular resistance. Applying this criterion to individual patients in the study, we find a clinically relevant reduction in flow split for patients with degrees of stenosis in the range from $56 \%$ to $79 \%$. These values range from $48 \%$ to $68 \%$ if we target a pressure gradient $>3.0 \mathrm{~mm}$ $\mathrm{Hg}$ across the LPA. This variability highlights the potential benefits of personalized simulation in predicting hemodynamic changes produced in specific patients as a result of stage II surgery, going beyond the clear limitations of average indicators.

To determine the potential clinical significance of varying degrees of LPA stenosis, we selected a quantitative criterion of the combination of an LPA:RPA flow split ratio $<30 \%$ and/or a mean pressure drop of $>3.0 \mathrm{~mm} \mathrm{Hg}$. This criterion is inspired by clinical practice, although decision making surrounding augmentation is primarily performed on a qualitative basis. For example, the indications for perioperative intervention on the pulmonary arteries typically consist of a gradient across the pulmonary artery segment of 2 to $4 \mathrm{~mm} \mathrm{Hg}$. Irregular geometry or a discrete area of pulmonary artery narrowing have been additional indications for pulmonary artery augmentation or stenting, even in the absence of a pressure gradient across the stenosis, as these geometries may become hemodynamically significant with exercise, despite exhibiting low flow rates at the time of catheterization. The LPA/RPA diameter ratio has also been used as an indicator for LPA plasty, ${ }^{3}$ with an angiographic LPA/RPA ratio of $<50 \%$ correlating highly with the judgment to perform a patch plasty.

The finding that a degree of stenosis of $>65 \%$ in diameter is required to produce clinically significant change under our definition fits with the concept of critical stenosis, as discussed, eg, in Berguer and Hwang, ${ }^{25}$ using a simple model of idealized flow through a cylindrical vessel. In that work, significant reductions in flow rate and pressure drop required a reduction of $>50 \%$ in diameter.

To bridge our quantitative definition of degree of LPA stenosis with metrics of visual inspection and expert judgment, we surveyed a cohort of pediatric cardiologists and surgeons to rank stenoses of varying severity. The outcome shows that only stenoses classified by the clinicians as severe produced clinically significant hemodynamic changes, and that these changes show a remarkable variability within the same class. This finding suggests a tendency to overtreat stenoses that are classified as moderate, although these stenoses did not meet our criteria for clinically significant hemodynamic changes. However, clinical decisions to treat or not should be considered additionally in the context of future growth and remodeling, as well as stress conditions, which were not considered in this study. Although legitimate nonhemodynamic reasons to aggressively treat mild or moderate stenosis may be present in some cases, these were not considered in the present study. Instead, the present study provides a controlled "virtual experiment" in which the consequences of stenosis on hemodynamics could be systematically examined independently of other clinical factors.

\section{Limitations}

We recognize several limitations of our study. The LPN model parameters were identified on the basis of preoperative stage II clinical data. The outcomes of stage II surgery were predicted using these parameters on a modified LPN layout and updated anatomic model. This approach assumes limited physiologic changes in the patients as a result of stage II surgery. Additional conditions, including pulmonary or cardiac dysfunction in the early postoperative period, or the development of collaterals or arteriovenous malformations, are not considered in our study. The predictions discussed in the present study are therefore most applicable in the short term after surgical recovery, particularly given that we have not modeled long-term growth in the pulmonary arteries. Such modeling would require development of new modeling approaches for pediatric growth and remodeling, which are currently lacking in the literature.

In addition, our clinical data are derived from sedated or anesthetized patients, whereas flow into the pulmonary arteries when the patient is in a usual state of awareness can 
vary greatly throughout the course of a day. Accounting for this variation in patient physiology will require new methods of uncertainty quantification. The increase of blood flow resulting from agitated states in infants, for example, may influence our results, if they indicate that lower degrees of stenosis are hemodynamically consequential. Simulating agitation or exercise in a multiscale model requires complicated assumptions that are outside the scope of this article but important for follow-up study. In addition, future work should account for uncertainties in the clinical data, to better characterize the variance associated with our predictions.

Larger clinical studies are warranted to correlate degree of stenosis with clinical outcomes and simulation predictions, before clinical application. Although direct application of the results of this study as determining factors in clinical decisions would be premature, they should be taken into consideration to separate the effects induced by LPA stenosis on the patients' hemodynamics from those related to growth and improved surgical outcome at later stages.

\section{CONCLUSIONS}

Multiscale numeric analysis on 6 single-ventricle patients was used to determine the minimum degree of stenosis in the LPA that results in deleterious SCPC hemodynamic and physiologic performance. The use of multiscale modeling allowed for a controlled experiment in which the hemodynamics of LPA stenosis could be examined independently of other confounding clinical factors. The results show that degrees of stenosis $<65 \%$ produce minimal effects on SCPC hemodynamics and physiology. The increase in complexity and risks of the SCPC operation with an extensive arterioplasty therefore may not be justified when the severity of stenosis is below this threshold, although unknowns remain related to the significance of LPA stenosis with exercise or stress, and subsequent growth and remodeling. Analysis of survey data confirms that most of the variability in the hemodynamic parameters is concentrated in the "severe" stenosis category, whereas lower degrees of stenosis are associated with limited impact on patient hemodynamics. Further studies examining effects of agitated (ie, exercise) states, pulmonary growth, physiologic changes from stage I-II, and the effect of errors in the clinical data are warranted. Finally, correlation with clinical data is needed to validate our findings.

The authors acknowledge the open-source Simvascular project at simtk.org.

\footnotetext{
References

1. Forbess JM, Cook N, Serraf A, Burke RP, Mayer JE, Jonas RA. An institutional experience with second-and third-stage palliative procedures for hypoplastic left heart syndrome: the impact of the bidirectional cavopulmonary shunt. J Am Coll Cardiol. 1997;29:665-70.

2. Bove EL. Surgical treatment for hypoplastic left heart syndrome. Jpn J Thorac Cardiovasc Surg. 1999;47:47-56.
}

3. Bichell DP, Lamberti JJ, Pelletier GJ, Hoecker C, Cocalis MW, Frank F, et al. Late left pulmonary artery stenosis after the Norwood procedure is prevented by a modification in shunt construction. Ann Thorac Surg. 2005;79: 1656-60.

4. Azakie A, McCrindle BW, Benson LN, Van Arsdell GS, Russell JL, Coles JG, et al. Total cavopulmonary connections in children with a previous Norwood procedure. Ann Thorac Surg. 2001;71:1541-6.

5. Moore JW, Spicer RL, Perry JC, Mathewson JW, Kirkpatrick SE, George L, et al. Percutaneous use of stents to correct pulmonary artery stenosis in young children after cavopulmonary anastomosis. Am Heart J. 1995;130:1245-9.

6. Pekkan K, Kitajima HD, de Zelicourt D, Forbess JM, Parks WJ, Fogel MA, et al. Total cavopulmonary connection flow with functional left pulmonary artery stenosis angioplasty and fenestration in vitro. Circulation. 2005;112:3264-71.

7. Schievano S, Migliavacca F, Coats L, Khambadkone S, Carminati M, Wilson N, et al. Percutaneous pulmonary valve implantation based on rapid prototyping of right ventricular outflow tract and pulmonary trunk from MR data. Radiology. 2007;242:490-7.

8. Snyder MF, Rideout VC, Hillestad RJ. Computer modeling of the human systemic arterial tree. J Biomech. 1968;1:341-53.

9. Corsini C, Baker C, Kung E, Schievano S, Arbia G, Baretta A, et al. An integrated approach to patient-specific predictive modeling for single ventricle heart palliation. Comput Methods Biomech Biomed Engin. 2013;17:1572-9.

10. Kung EO, Baretta A, Baker C, Arbia G, Biglino G, Corsini C, et al. Predictive modeling of the virtual hemi-Fontan operation for second stage single ventricle palliation: two patient-specific cases. J Biomech. 2013;46:423-9.

11. Baker CE, Corsini C, Cosentino D, Dubini G, Pennati G, Migliavacca F, et al. Effects of pulmonary artery banding and retrograde aortic arch obstruction on the hybrid palliation of hypoplastic left heart syndrome. J Thorac Cardiovasc Surg. 2013;146:1341-8.

12. Baretta A, Corsini C, Yang W, Vignon-Clementel IE, Marsden AL, Feinstein JA, et al. Virtual surgeries in patients with congenital heart disease: a multi-scale modelling test case. Philos Trans A Math Phys Eng Sci. 2011;369:4316-30.

13. Spilker RL, Feinstein JA, Parker DW, Reddy VM, Taylor CA. Morphometry-based impedance boundary conditions for patient-specific modeling of blood flow in pulmonary arteries. Ann Biomed Eng. 2007;35:546-59.

14. Migliavacca F, Pennati G, Dubini G, Fumero R, Pietrabissa R, Urcelay G, et al. Modeling of the Norwood circulation: effects of shunt size, vascular resistances, and heart rate. Am J Physiol Heart Circ Physiol. 2001;280:H2076-86.

15. Esmaily-Moghadam M, Vignon-Clementel IE, Figliola R, Marsden AL. A modular numerical method for implicit 0D/3D coupling in cardiovascular finite element simulations. J Comput Phys. 2013;244:63-79.

16. Taylor CA, Hughes TJR, Zarins CK. Finite element modeling of blood flow in arteries. Comp Methods Appl Mech Eng. 1998;158:155-96.

17. Esmaily-Moghadam M, Bazilevs Y, Hsia TY, Vignon-Clementel IE, Marsden AL A comparison of outlet boundary treatments for prevention of backflow divergence with relevance to blood flow simulations. Comput Mech. 2011;48: 277-91.

18. Esmaily-Moghadam M, Bazilevs Y, Marsden AL. A new preconditioning technique for implicitly coupled multidomain simulations with applications to hemodynamics. Comput Mech. 2013;52:1141-52.

19. Franch RH, Brit BG. Congenital stenosis of the pulmonary artery branches: a classification, with postmortem findings in two cases. Am J Med. 1963;35:512-29.

20. Weber HS, Myers JL. Association of asymmetric pulmonary artery growth following palliative surgery for hypoplastic left heart syndrome with ductal coarctation, neoaortic arch compression, and shunt-induced pulmonary artery stenosis. Am J Cardiol. 2003;91:1503-6.

21. Biglino G, Giardini A, Ntsinjana HN, Schievano S, Hsia TY, Taylor AM. Ventriculoarterial coupling in palliated hypoplastic left heart syndrome: noninvasive assessment of the effects of surgical arch reconstruction and shunt type. J Thorac Cardiovasc Surg. 2014;148:1526-33.

22. Szopos M, Poussineau N, Maday Y, Canniffe C, Celermajer DS, Bonnet D, et al. Computational modeling of blood flow in the aorta-insights into eccentric dilatation of the ascending aorta after surgery for coarctation. J Thorac Cardiovasc Surg. 2014;148:1572-82.

23. Taber LA. Biomechanics of growth, remodeling, and morphogenesis. Appl Mech Rev. 1995;48:487-545.

24. Agnoletti G, Boudjemline Y, Bonnet D, Sidi D, Vouhe P. Surgical reconstruction of occluded pulmonary arteries in patients with congenital heart disease effects on pulmonary artery growth. Circulation. 2004;109:2314-8.

25. Berguer R, Hwang NH. Critical arterial stenosis: a theoretical and experimental solution. Ann Surg. 1974;180:39-50. 

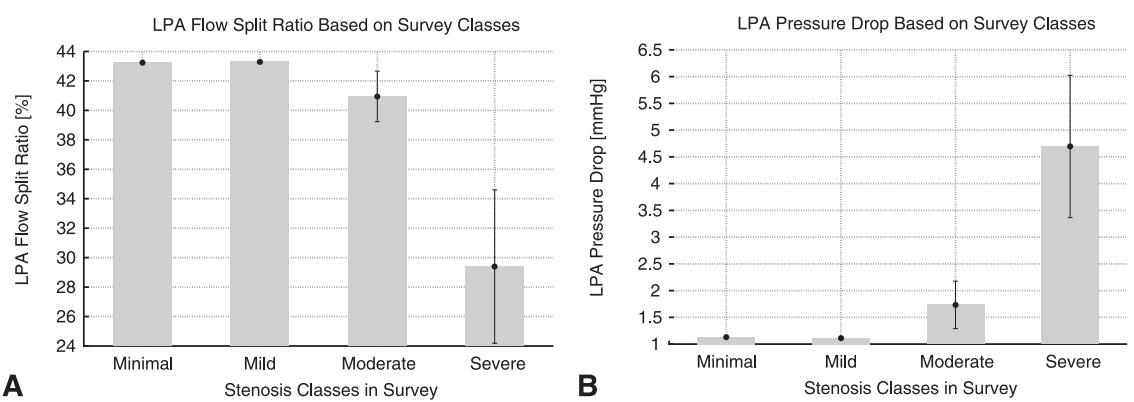

FIGURE E1. A, Average value and SD for LPA flow split ratio; and (B) pressure drop for all surveyed classes. Error bars are based on 1 SD. $L P A$, Left pulmonary artery. 
TABLE E1. LPN circulation model parameters for the 6 patients considered in this study

\begin{tabular}{|c|c|c|c|c|c|c|}
\hline LPN blocks parameters & P1 & $\mathbf{P 2}$ & $\mathbf{P 3}$ & P4 & P5 & P6 \\
\hline \multicolumn{7}{|l|}{ Heart } \\
\hline \multicolumn{7}{|l|}{ Atrium } \\
\hline CSA & 0.500 & 0.400 & 1.900 & 1.868 & 1.292 & 1.068 \\
\hline $\mathrm{cSA}$ & 0.3 & 0.2 & 0.2 & 0.2 & 0.2 & 0.1 \\
\hline dSA & 0.40 & 0.38 & 0.18 & 0.22 & 0.18 & 0.13 \\
\hline VSA0 & 1.630 & 1.460 & 1.324 & 1.280 & 1.368 & 14.101 \\
\hline tSAs & 0.120 & 0.220 & 0.190 & 0.188 & 0.216 & 0.202 \\
\hline $\mathrm{t} 1$ & 0.000 & 0.050 & 0.052 & 0.051 & 0.067 & 0.043 \\
\hline \multicolumn{7}{|l|}{ Ventricle } \\
\hline $\mathrm{a}$ & -0.115 & -0.129 & -0.110 & -0.129 & -0.129 & -0.170 \\
\hline $\mathrm{b}$ & 12.0 & 8.5 & 11.0 & 8.3 & 8.0 & 14.0 \\
\hline $\mathrm{cSV}$ & $1.800 \times 10^{-4}$ & 1.422 & $1.390 \times 10^{-1}$ & 1.420 & 1.420 & 1.422 \\
\hline dSV & 0.600 & 0.070 & 0.160 & 0.065 & 0.055 & 0.054 \\
\hline VSV0 & 3.800 & 3.400 & 6.180 & 2.987 & 3.193 & 3.802 \\
\hline tSVs & 0.280 & 0.310 & 0.317 & 0.313 & 0.360 & 0.289 \\
\hline RMYO & 0.040 & 0.045 & 0.050 & 0.051 & 0.048 & 0.040 \\
\hline \multicolumn{7}{|l|}{ Valves } \\
\hline LAV & $2.640 \times 10^{-5}$ & $2.740 \times 10^{-5}$ & $2.827 \times 10^{-5}$ & $2.859 \times 10^{-5}$ & $2.796 \times 10^{-5}$ & $2.638 \times 10^{-5}$ \\
\hline KAV & $7.020 \times 10^{-4}$ & $8.160 \times 10^{-4}$ & $9.256 \times 10^{-4}$ & $9.685 \times 10^{-4}$ & $8.861 \times 10^{-4}$ & $7.019 \times 10^{-4}$ \\
\hline $\mathrm{KAO}$ & $7.390 \times 10^{-5}$ & $8.590 \times 10^{-5}$ & $9.740 \times 10^{-5}$ & $1.019 \times 10^{-4}$ & $9.327 \times 10^{-5}$ & $7.388 \times 10^{-5}$ \\
\hline \multicolumn{7}{|l|}{ Upper body } \\
\hline RUBA & 0.843 & 2.010 & 1.367 & 1.153 & 1.071 & 2.101 \\
\hline LUBA & $6.470 \times 10^{-4}$ & $6.560 \times 10^{-4}$ & $6.620 \times 10^{-4}$ & $6.650 \times 10^{-4}$ & $6.601 \times 10^{-4}$ & $6.474 \times 10^{-4}$ \\
\hline CUB & 1.810 & 0.570 & 0.948 & 1.189 & 1.313 & 0.536 \\
\hline RUBV & 2.46 & 5.87 & 3.99 & 3.36 & 3.12 & 6.13 \\
\hline CSVC & 0.226 & 0.256 & 0.049 & 0.060 & 0.070 & 0.067 \\
\hline \multicolumn{7}{|l|}{ Lower body } \\
\hline \multicolumn{7}{|l|}{ Aorta } \\
\hline $\mathrm{CAO}$ & 0.141 & 0.150 & 0.145 & 0.181 & 0.168 & 0.074 \\
\hline RTHAO & 0.223 & 0.288 & 1.309 & 1.507 & 1.974 & 3.924 \\
\hline LTHAO & $2.200 \times 10^{-3}$ & $2.280 \times 10^{-3}$ & $2.350 \times 10^{-3}$ & $2.380 \times 10^{-3}$ & $2.328 \times 10^{-3}$ & $2.196 \times 10^{-3}$ \\
\hline СТHAO & $2.960 \times 10^{-2}$ & $2.100 \times 10^{-2}$ & $3.050 \times 10^{-2}$ & $2.528 \times 10^{-2}$ & $1.764 \times 10^{-2}$ & $7.058 \times 10^{-3}$ \\
\hline RABAO & 1.700 & 2.190 & 1.413 & 1.628 & 2.132 & 4.238 \\
\hline LABAO & $2.200 \times 10^{-3}$ & $2.280 \times 10^{-3}$ & $2.353 \times 10^{-3}$ & $2.380 \times 10^{-3}$ & $2.328 \times 10^{-3}$ & $2.196 \times 10^{-3}$ \\
\hline CABAO & $6.260 \times 10^{-2}$ & $4.450 \times 10^{-2}$ & $1.290 \times 10^{-2}$ & $1.069 \times 10^{-2}$ & $7.463 \times 10^{-3}$ & $2.986 \times 10^{-3}$ \\
\hline \multicolumn{7}{|l|}{ Legs } \\
\hline RLEGA & 4.630 & 6.730 & 5.254 & 6.717 & 8.199 & 13.552 \\
\hline LLEGA & $2.200 \times 10^{-3}$ & $2.280 \times 10^{-3}$ & $2.353 \times 10^{-3}$ & $2.380 \times 10^{-3}$ & $2.328 \times 10^{-3}$ & $2.196 \times 10^{-3}$ \\
\hline CLEGA & $3.040 \times 10^{-2}$ & $1.850 \times 10^{-2}$ & $2.566 \times 10^{-2}$ & $1.849 \times 10^{-2}$ & $1.418 \times 10^{-2}$ & $7.261 \times 10^{-3}$ \\
\hline RLEGC & 10.930 & 15.890 & 12.412 & 15.867 & 19.368 & 32.012 \\
\hline CLEGV & 0.620 & 0.376 & 0.523 & 0.377 & 0.289 & 0.148 \\
\hline RLEGV & 2.550 & 3.710 & 2.896 & 3.702 & 4.519 & 7.469 \\
\hline \multicolumn{7}{|l|}{ IVC } \\
\hline CABIVC & 0.322 & 0.229 & 0.364 & 0.275 & 0.192 & 0.077 \\
\hline RABIVC & $4.670 \times 10^{-2}$ & $5.390 \times 10^{-2}$ & $3.465 \times 10^{-2}$ & $4.131 \times 10^{-2}$ & $5.783 \times 10^{-2}$ & $1.369 \times 10^{-1}$ \\
\hline V0ABIVC & 4.160 & 3.720 & 3.385 & 3.272 & 3.497 & 4.165 \\
\hline CTHIVC & 0.965 & 0.069 & 0.218 & 0.165 & 0.115 & 0.184 \\
\hline RTHIVC & $3.640 \times 10^{-2}$ & $8.380 \times 10^{-2}$ & $2.695 \times 10^{-2}$ & $3.213 \times 10^{-2}$ & $4.498 \times 10^{-2}$ & $1.065 \times 10^{-1}$ \\
\hline VOTHIVC & 5.460 & 4.880 & 4.434 & 4.286 & 4.582 & 5.457 \\
\hline \multicolumn{7}{|l|}{ Liver } \\
\hline RLA & 26.530 & 30.300 & 24.200 & 29.847 & 39.090 & 77.696 \\
\hline $\mathrm{CL}$ & 0.779 & 0.652 & 0.880 & 0.665 & 0.464 & 0.186 \\
\hline RLV & 0.166 & 0.190 & 0.152 & 0.187 & 0.245 & 0.487 \\
\hline \multicolumn{7}{|l|}{ Kidneys } \\
\hline RKA & 18.690 & 21.340 & 17.046 & 21.024 & 27.535 & 54.729 \\
\hline
\end{tabular}


TABLE E1. Continued

\begin{tabular}{|c|c|c|c|c|c|c|}
\hline LPN blocks parameters & P1 & P2 & P3 & P4 & P5 & P6 \\
\hline CK & 0.324 & 0.272 & 0.366 & 0.277 & 0.193 & 0.077 \\
\hline RKV & 1.750 & 1.999 & 1.596 & 1.969 & 2.579 & 5.126 \\
\hline \multicolumn{7}{|l|}{ Intestine } \\
\hline RIA & 40.970 & 46.790 & 37.370 & 46.088 & 60.360 & 119.973 \\
\hline $\mathrm{CI}$ & 0.194 & 0.160 & 0.219 & 0.166 & 0.116 & 0.046 \\
\hline RIV & 0.745 & 0.851 & 0.679 & 0.838 & 1.097 & 2.181 \\
\hline \multicolumn{7}{|l|}{ Lungs } \\
\hline \multicolumn{7}{|l|}{ Total resistance } \\
\hline $\mathrm{Rl}$ & 2.911 & 1.361 & 0.616 & 1.701 & 1.138 & 1.054 \\
\hline $\mathrm{Rr}$ & 1.692 & 1.129 & 0.662 & 1.230 & 1.444 & 0.902 \\
\hline \multicolumn{7}{|l|}{ Respiration } \\
\hline P0ith & 0.0 & 0.0 & 0.0 & 0.0 & 0.0 & 0.0 \\
\hline P0iab & 0.0 & 0.0 & 0.0 & 0.0 & 0.0 & 0.0 \\
\hline APith & 0.0 & 0.0 & 0.0 & 0.0 & 0.0 & 0.0 \\
\hline APiab & 0.0 & 0.0 & 0.0 & 0.0 & 0.0 & 0.0 \\
\hline tsr & 0.430 & 0.430 & 0.430 & 0.430 & 0.430 & 0.430 \\
\hline
\end{tabular}

Values for $\mathrm{R}, \mathrm{L}$, and $\mathrm{K}$ are given in $\mathrm{mm} \mathrm{Hg} \cdot \mathrm{s} / \mathrm{ml}$; values for $\mathrm{C}$ are given in $\mathrm{ml} / \mathrm{mm} \mathrm{Hg}$; values for $\mathrm{V}$ are given in $\mathrm{ml}$; and values for $\mathrm{P}$ and $\mathrm{AP}$ are given in $\mathrm{mm} \mathrm{Hg}$. $L P N$, Lumped parameter network; $P$, patient ( $P 1$, patient 1 , etc); $C S A$, atrial model parameters; $d S A$, atrial model parameters; VSAO, initial atrial volume; $t S A s$, atrial activation time; $t 1$, atrioventricular activation time overlap; $a$, arterial; $b$, ventricular model parameters; $c S V$, superior vena cava compliance; $d S V$, ventricular model parameters; $V S V O$, initial ventricular volume; $t S V s$, ventricle activation time; $R M Y O$, myocardial resistance; $L A V$, atrio-ventricular inductance; $K A V$, atrio-ventricular resistance; $K A O$, aortic resistance; $R U B A$, arterial upper body resistance; $L U B A$, arterial upper body inductance; $C U B$, upper body capacitance; $R U B V$, venous upper body resistance; $C S V C$, superior vena cava compliance; $C A O$, aortic compliance; $R T H A O$, thoracic aorta resistance; $L T H A O$, thoracic aorta inductance; $C T H A O$, compliance in thoracic aorta; $R A B A O$, resistance in abdominal aorta; $L A B A O$, inductance in abdominal aorta; $C A B A O$, compliance of abdominal aorta; $R L E G A$, lower body arterial resistance; $L L E G A$, lower body arterial inductance; $R L E G C$, lower body capillary resistance; $C L E G V$, lower body arterial flow rate; $R L E G V$, lower body venous resistance; $C A B I V C$, compliance of abdominal inferior vena cava; $R A B I V C$, resistance in abdominal inferior vena cava; $R T H I V C$, thoracic inferior vena cava resistance; $R L A$, hepatic arterial resistance; $C L$, hepatic compliance; $R L V$, hepatic venous resistance; $R K A$, renal arterial resistance; $C K$, renal compliance; $R K V$, renal venous resistance; $R I A$, arterial resistance in the intestine; $C I$, intestine compliance; $R I V$, venous resistance in the intestine; $R l$, left pulmonary vascular resistance; $R r$, right pulmonary vascualar resistance; POith, respiration model parameters; $P O i a b$, respiration model parameters; $A P i t h$, respiration model parameters; $A P i a b$, respiration model parameters; $t s r$, respiration model parameters; $R$, resistance; $L$, inductance; $C$, compliance; $V$, venous; $P$, pressure.

TABLE E2. Average degrees of stenosis and associated SDs resulting from the analysis of survey data

\begin{tabular}{lccrrrr}
\hline Stenosis type & Occurrences & Statistic & Def. A & Def. B & Def. C & Def. D \\
\hline Minimal & \multirow{2}{*}{ Overage } & 32.84 & 29.05 & 53.89 & 48.97 \\
stenosis (\%) & & SD & 10.66 & 8.82 & 11.67 & 11.18 \\
Mild stenosis (\%) & \multirow{2}{*}{20} & Average & 44.78 & 37.02 & 67.50 & 59.21 \\
& & SD & 14.54 & 10.87 & 16.34 & 13.84 \\
Moderate & \multirow{2}{*}{25} & Average & 52.70 & 49.03 & 77.00 & 73.59 \\
stenosis (\%) & & SD & 8.08 & 6.65 & 8.29 & 6.99 \\
Severe stenosis & \multirow{2}{*}{36} & Average & 70.45 & 70.37 & 90.55 & 90.42 \\
$(\%)$ & & SD & 8.57 & 9.07 & 5.83 & 6.27 \\
\hline
\end{tabular}

Def. A, Def. B, Def. C, and Def. D are diameter-based definitions of stenosis using

$\mathrm{d}_{\mathrm{ref}, 1}, \mathrm{~d}_{\mathrm{ref}, 2}, \mathrm{~d}_{\mathrm{ref}, 1}$, and $\mathrm{d}_{\mathrm{ref}, 2}$, respectively. Def., Definition; $S D$, standard deviation.

TABLE E3. Minimum, maximum, and average percentage change for relevant hemodynamic parameters resulting from changing the degree of stenosis from $35 \%$ to $80 \%$ based on diameter

\begin{tabular}{lcccccc}
\hline \multicolumn{1}{c}{ Quantity } & P1 & P2 & P3 & P4 & P5 & P6 \\
\hline Qp/Qs & $0.34 / 0.01 / 1.18$ & $0.74 / 0.22 / 1.74$ & $0.99 / 0.20 / 2.08$ & $1.18 / 0.27 / 2.42$ & $0.79 / 0.07 / 2.13$ & $0.42 / 0.10 / 0.88$ \\
Power loss & $73.55 / 4.18 / 239.45$ & $87.77 / 23.36 / 143.83$ & $198.83 / 66.82 / 285.63$ & $93.99 / 41.02 / 130.42$ & $581.01 / 84.48 / 1240.72$ & $123.72 / 46.65 / 172.66$ \\
Ventricular power & $0.89 / 0.05 / 3.07$ & $1.50 / 0.24 / 3.60$ & $3.34 / 0.73 / 6.94$ & $3.81 / 0.89 / 7.63$ & $3.04 / 0.33 / 8.04$ & $1.98 / 0.44 / 4.10$ \\
Systemic $\mathrm{O}_{2}$ saturation* & $0.15 / 0.01 / 0.52$ & $0.23 / 0.03 / 0.56$ & $0.60 / 0.12 / 1.28$ & $0.44 / 0.09 / 0.90$ & $0.30 / 0.03 / 0.82$ & $0.17 / 0.04 / 0.36$ \\
Venous $\mathrm{O}_{2}$ saturation* & $0.27 / 0.01 / 0.92$ & $0.35 / 0.05 / 0.85$ & $0.96 / 0.19 / 2.05$ & $0.76 / 0.17 / 1.56$ & $0.64 / 0.06 / 1.75$ & $0.39 / 0.09 / 0.84$ \\
SVC pressure & $1.68 / 0.09 / 5.75$ & $9.17 / 1.52 / 22.01$ & $11.61 / 2.50 / 24.30$ & $10.68 / 2.44 / 21.57$ & $10.51 / 1.08 / 28.07$ & $16.18 / 3.64 / 33.60$ \\
SVC flow rate & $0.58 / 0.03 / 1.99$ & $1.07 / 0.16 / 2.59$ & $1.79 / 0.37 / 3.77$ & $2.4 / 0.54 / 4.88$ & $2.04 / 0.20 / 5.49$ & $1.21 / 0.29 / 2.55$ \\
\hline
\end{tabular}

Values are given as \%: average/minimum/maximum. $Q p / Q s$, Pulmonary-to-systemic flow ratio; $S V C$, superior vena cava. *Computed assuming a systemic oxygen flow rate consumption of $126.12 \mathrm{BSA} / 60 \mathrm{mLO}_{2} / \mathrm{s}$ and maximum and actual $\mathrm{O}_{2}$ concentration equal to $\mathrm{C}_{\max }=0.2144$ and $0.94 \mathrm{C}_{\max }$, respectively. 